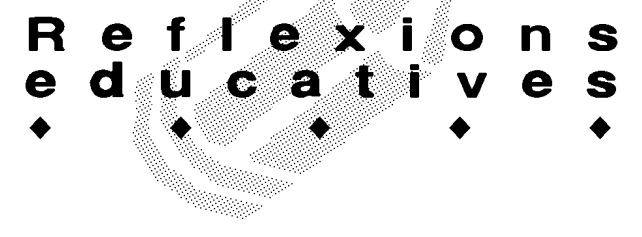

\title{
LA NORA NO PARLA
}

\section{Inés Tomás Alabart. Àrea de Personalitat, Avaluació i Tractament Psicològic. URV}

Els pares de la Nora (aquest és un nom fictici) decideixen portar-la a la consulta d'un psicòleg, a instàncies de la seva mestra. El motiu és que la nena, de quatre anys, no parla absolutament genys quan és fora de casa i dins l'àmbit familiar només ho fa si la mare hi és present.

Abans de continuar, voldria remarcar la importància de la figura del mestre a l'hora de detectar possibles disfuncions psíquiques en el seus alumnes i fer, d'una forma adequada, la derivació al professional pertinent. En aquest cas la Nora té la sort de trobar-se amb una professora que té molt en compte les qüestions psíquiques del seu alumnat. Ella intenta, durant tot un curs escolar, comprendre i permetre l'adaptació de la Nora al col-legi, però davant aquesta impossibilitat espera al curs vinent; veient que passava el mateix amb la mestra de P4, totes dues decideixen que han de parlar amb els pares i insistir en aquesta qüestió que altres vegades han plantejat més suaument $i$ que no ha trobat una resposta adequada per part d'ells.

\section{Primera entrevista amb els pares}

Els pares de la Nora tenen 42 anys ell, i 39 la mare. La Nora té dos germans més, de 17 i 16 anys, respectivament. Preguntats per aquesta diferencia d'edat, diuen que no van anar a buscar-la, però un cop van saber de l'embaràs els va fer il.lusió.

En relació al seu desenvolupament, van remarcar que va seguir una evolució adequada en tots els aspectes, excepte en el llenguatge, que va iniciar al voltant dels dos anys i mig. També li ha costat molt l'adquisició d'hàbits tals com posar-se l'abric, rentar-se, etc.

Consideren que està molt enganxada a la mare, $i$ quan se li pregunta sobre el tema de la parla es posa a plorar. A l'única que respon és a la mare, tot dient-li que ja parlarà quan sigui gran. Afegeixen que és una nena molt sensible (si la renyen, plora d'una forma que ells consideren excessiva), i té molta gelosia de la relació entre els pares, de manera que es posa sempre entremig amb qualsevol excusa quan ells estan parlant.

L'actitud d'ells durant la entrevista és de molta inhibició. Només parlen si la terapeuta va fent preguntes. La mare sempre contesta amb un "no sé", mentre que el pare fa la impressió d'estar molt segur de tot el que diu. També manifesten que tenen ganes de resoldre el problema, però ho veuen molt difícil, perquè ja han provat de tot.

Els plantejo tenir una o dues entrevistes amb la nena i després tornar-los a citar per tal de comentar-los com veig la situació.

\section{Primera entrevista amb la Nora}

La Nora arriba amb cara de contenta, i la mare li recomana que es porti bé. Quan passem a la consulta es queda parada al mig, amb l'abric possat. No accepta cap dels suggeriments que jo li faig i es queda allí dreta més de mitja hora, movent la cama d'una forma compuIsiva i amb els ulls brillants, a punt de plorar. Quan li pregunto directament per la seva actitud, trenca a plorar i vol apropar-se a mí físicament parlant, però no pot.

\section{Segona entrevista amb la Nora}

S'asseu a terra i per senyes em demana que li tregui l'abric, cosa a la qual accedeixo. Després d'això es queda allà, asseguda, observant-me a mi i al seu cos alternativament, fins que torna a plorar i s'apropa a mi buscant un contacte corporal.

Quan cito als pares, òbviament no tinc gaire cosa nova per dir-los. Els plantejo clarament que la inhibició i autocontrol de la Nora són excessius, i que alguna cosa molt forta per a ella ha de estar sostenint aquesta situació. Els dic també que jo no sé què pot ser això i que l'única forma d'investigar-ho i ajudar-la a resoldre el conflicte, un cop coneguda la causa, és que ella vagi venint a una teràpia que anirà paral.lela al diagnòstic, i que necessitaré comptar amb ells per fer-ho. Ho accepten i comencem la tasca.

Òbviament, no és aquest l'espai per transcriure literalment totes les sessions que es van realitzar durant tot un any, a raó de dues semanals. II.lustraré, doncs, aquelles que em semblen més representatives de la seva evolució.

\section{Evolució de la teràpia}

La Nora continua plorant al final de les nostres trobades i després de molta estona de controlar-se. Li plantejo que les sesions han de servir per ajudar-la a 


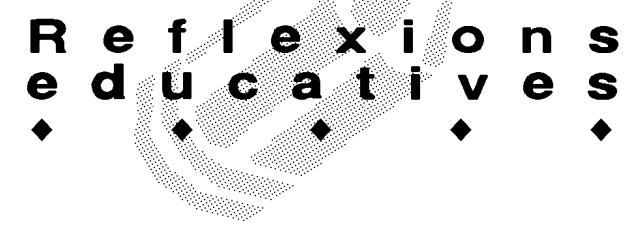

resoldre el seu problema i no per convertir-se en un de més; així és que, si no vol parlar, ni jugar, no passa res. És el primer dia que no plora.

A la sessió següent (que ja és la nostra setena trobada), per primer cop anomena un objecte. Ho fa en el context d'un joc de cartes que jo li proposo i que implica que ella m'ha d'anar demanant coses a mi, però no a l'inrevés.

A partir d'aquesta actuació, verbalitzada per mi, es dóna un canvi important a la teràpia i pot anar contestant les preguntes que li faig en relació a la família i a l'escola.

Veiem, doncs, un element important pel que fa a l'etiologia de la seva posició psíquica: la Nora no té espai per demanar. Se li han donat i fet les coses abans que les demanés. I al mateix temps, a ella se li ha demanat massa per poder interactuar. Aquesta situació de fet apareix confirmada a les entrevistes posteriors amb la mare.

Les sessions següents es caracteritzen per jocs vinculats a l'acció d'amagar. Es posa d'esquena a mi o parapetada darrere de la seva capsa de joguines, perquè jo no vegi el que fa. Si ho miro, s'atura. Novament apareix el control excessiu de l'altre, la hipervigilància. Li pregunto per aquesta qüestio i riu molt.

Comença aleshores un joc de tipus regressiu: es mira les mans, les colpeja, s'enrosca els dits i després agafa la plastilina i va modelant coses. Decideixo ser un mirall en el que ella es puguir veure reflectida per continuar ajudant-la en l'elaboració del seu conflicte i jo també agafo la plastilina. No hi ha paraules, però ens anem mostrant el que fem i desfem.

La sessió finalitza amb un nino enterrat dins la plastilina, que va traient el cap de la massa per poder sortir fora. És un procés laboriós per la gran quantitat de plastilina que ha utilitzat, però finalment ho aconsegueix i s'està força estona novament per netejar el nino. Aquest joc permet parlar del seus germans i diu que ells "també" la vigilen. Donat aquest "també", pregunto qui més ho fa, i no obtinc resposta.

Decideixo plantejar una sessió de treball conjunta amb la mare i la Nora, que resumeixo a continuació:

La Nora i la seva mare seuen a terra i la nena li va ensenyant totes les joguines que té a la capsa. La mare pregunta què han de fer amb elles i la nena respon que, de moment, mirar-les. Després li dóna la plastilina, però la mare diu que ella no en sap i que hi jugui sola. La Nora comença a modelar i a rebre les posteriors crítiques de la mare, perquè el que fa no s'assembla a res. No ho fa enfadada, sinó rient. Finalment la Nora s'atura i li diu que juguin amb els ninos. La mare proposa un joc consistent a ordenar tots els joguets de la capsa, de petit a gran. Malgrat l'enfadament de la Nora perquè diu que això no ho sap fer, la mare va iniciant el joc. Finalment fan dues cases: una per als ninos grans i l'altra per als petits. La Nora va posar la seva mare amb els germans i ella es queda amb el pare. Això provoca un rebuig molt gran de la mare i li diu que això no és ordenar i que pot anar-se'n a cuidar els animals d'una granja que han construït.

La resta de la sessió es caracteritza per la impossibilitat de la mare d'assumir una funció lúdica.
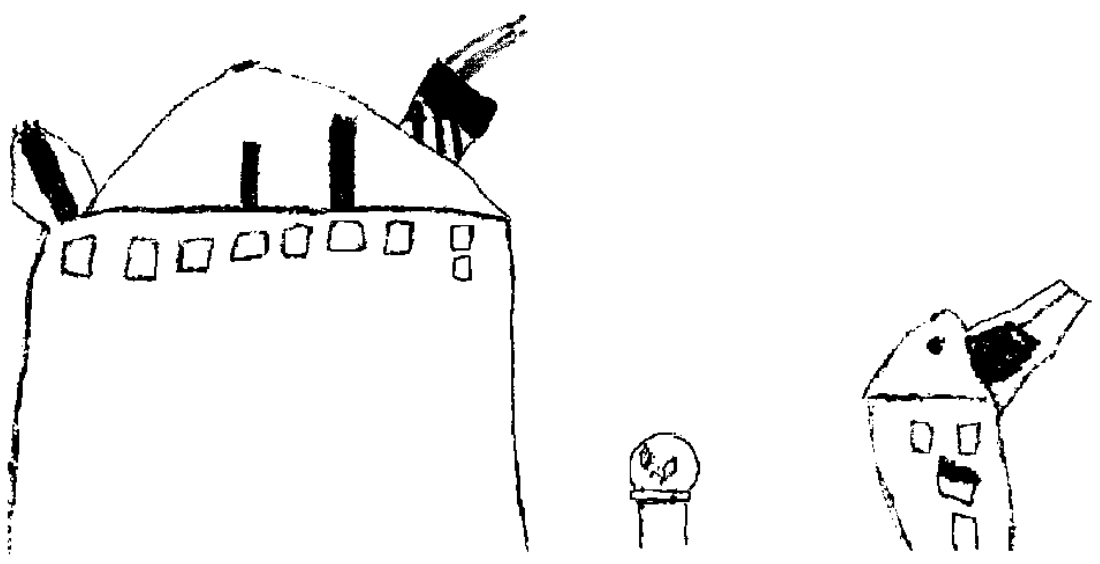


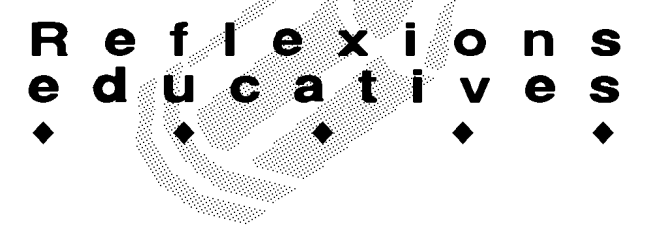

Ella continua interpretant els jocs de la Nora des de la lògica cognitiva de l'adult: ¿Com pot ser que un elefant condueixi el camió?

Aquesta sessió permet treballar després amb la mare tots els aspectes d'exigència i control excessius en relació a la Nora. Com ve ella sola, pot deixar-se molt més, plorar i parlar de les seves dificultats per decidir per si sola. En aquest sentit pensa que laNora i ella s'assemblen molt i que ella ha utilitzat la nena de companyia en un moment en què la seva relació de parella estava ja molt malmesa.

La Nora passa les sessions següents jugant a repetir el que va fer amb la mare, però, ara sí, acabant la historia com ella vol i que és sempre de la mateixa manera: la mare amb els germans i ella amb aquest pare que en la realitat està tan absent.

Ja no necessita que no la miri per jugar i comença a representar gráficament, allò que fa en el joc prèviament. És en aquest moment de la teràpia que un dia em diu molt contenta que ha après una cançó nova i que si la pot cantar. Li dic que sí, i la cançó en qüestió és: "Ay, mama Inés".

Passa després a una fase de grafismes aparentment sense significat, que jo vaig repetint en un altre full per a satisfacció seva. La progressió en aquests grafismes acaba el dia que pot dibuixar-se a sí mateixa i escriure el seu nom.

Comença a jugar sola amb els ninos de la granja i jo em poso dins al joc. S'enfada molt perquè no li he demanat permís per fer-ho i davant la meva posició de continuar-hi, em diu que m'assemblo al seu pare, que sempre està manant, i la mare i ella han de fer el que ell vol. Li plantejo altres possibilitats de relació i passem a muntar un joc totes dues. Acaba posant totes les coses de la capsa en un espai que hem construït amb plastilina, i deixa fora el nino més petit perquè ja no hi cap. Li assenyalo la paradoxa i a partir d'aquí la Nora pot verbalitzar el seu sentiment de soledat en el món dels adults, la identificació amb una mare que tampoc no parla, en el sentit simbòlic del mot. La Nora experimenta en el dia a dia de les sessions que, encara que sigui dona i petita, pot construir un espai propi i interactuar amb els altres.

La seva integració al col-legi és ja total i donem per acabat el tractament, ja que els pares no poden implicarse com a parella per treballar els seus conflictes. Dos anys després la mare em truca per telèfon per comunicarme que canvien de país pels canvis en la feina del marit i que abans de marxar volia acomiadar-se de mi.

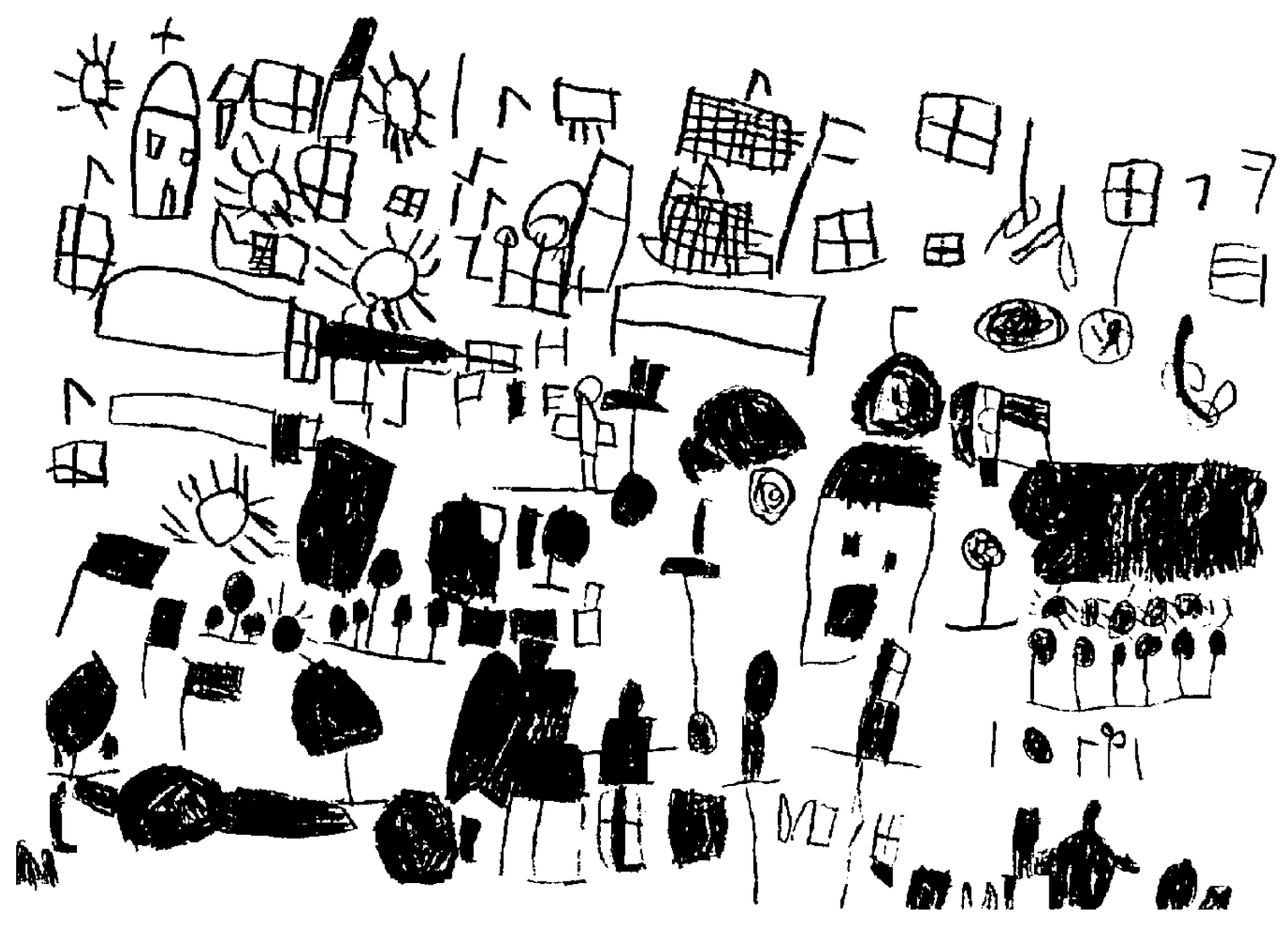

